\title{
Review Article \\ Remote Sensing Applications in Tobacco Yield Estimation and the Recommended Research in Zimbabwe
}

\author{
Ezekia Svotwa, ${ }^{1}$ Anxious J. Masuka, ${ }^{1}$ Barbara Maasdorp, ${ }^{2}$ \\ Amon Murwira, ${ }^{3}$ and Munyaradzi Shamudzarira ${ }^{1}$ \\ ${ }^{1}$ Tobacco Research Board, Kutsaga Research Station, Harare, Zimbabwe \\ ${ }^{2}$ Department of Crop Science, University of Zimbabwe, Zimbabwe \\ ${ }^{3}$ Department of Geography and Environmental Studies, University of Zimbabwe, Zimbabwe
}

Correspondence should be addressed to Ezekia Svotwa; esvotwa2@gmail.com

Received 30 September 2013; Accepted 28 October 2013

Academic Editors: O. Ferrarese-Filho and C. Tsadilas

Copyright (C) 2013 Ezekia Svotwa et al. This is an open access article distributed under the Creative Commons Attribution License, which permits unrestricted use, distribution, and reproduction in any medium, provided the original work is properly cited.

Tobacco crop area and yield forecasts are important in stabilizing tobacco prices at the auction floors. Tobacco yield estimation in Zimbabwe is currently based on statistical surveys and ground-based field reports. These methods are costly, time consuming, and are prone to large errors. Remote sensing can provide timely information on crop spectral characteristics which can be used to estimate crop yields. Remote sensing application on agriculture in Zimbabwe is still very limited. Research should focus on identifying suitable reflectance indices that are related to tobacco growth and yield. Varietal yield response to fertiliser and planting dates as well as suitable temporal windows for spectral data collection should be identified. The challenges of the different tobacco land sizes have to be overcome by identifying suitable satellite platform, with sufficient spectral resolution to separate the tobacco crop from the adjacent competing crops and noncrop vegetative surfaces. The identified suitable index should be strongly correlated with tobacco in season dry mass and yield. The suitable vegetative indices can be employed in establishing tobacco cropped area and then apply the long-term area yield relationship from government and nongovernmental statistical departments to estimate yield from remote sensing derived cropped area.

\section{Background}

Zimbabwe is the largest producer of tobacco in Africa and the world's fourth-largest producer of flue-cured tobacco (Nicotiana tabacum), after China, Brazil, and the United States of America. Tobacco production has been the leading driver behind the $34 \%$ growth in Zimbabwe's agriculture and one of the major sources of foreign currency [1]. Tobacco crop plays an important role in the economy of Zimbabwe and in the 2012/2013 marketing season, 144 million kg of tobacco was sold, earning the country $\$ 525$ million [2].

Crop area and yield forecasts play an important role in stabilizing tobacco prices at the auction floors. Crop forecasting is the art of predicting crop yields and production before the harvest actually takes place, typically a couple of months in advance [2]. Zimbabwe mostly relies on crop statistical forecasting/estimation, crop reports/field visits from extension officers, and statistical crop forecasts for crop yield forecasts [3]. However, data from crop estimates, which are obtained through surveys conducted after harvests, are in most countries available quite late for early warning purposes.

Crop yield estimation in many countries is based on conventional techniques of data collection and ground-based field reports [4]. A variety of mathematical models relating to crop yield have also been proposed in recent years for many crops [4, 5]. In Zimbabwe crop surveys are mostly used in estimating crop yield [3]. The method is costly, time consuming, and prone to large errors due to incomplete ground observations, leading to poor crop yield assessment and crop area estimations [4]. 


\section{Remote Sensing Applications in Crop Area Assessment}

Remote sensing is defined as acquiring information about an object without physically getting into contact with it. Remote sensing has been used for some time to characterize properties of vegetation, to estimate yield, to estimate total biomass, and to monitor plant health and plant stress [6]. The interaction of the incident energy with the atomic structures of soil, rocks, plants, bodies of water, man-made objects, and so forth governs how much energy is absorbed and thus how much is reflected [7]. It is this reflected and absorbed energy that is picked up by the remote sensing devices, which is used to characterize the properties of a plant.

Visible (reflected light) and near-infrared (absorbed light) can be used to detect plant stress as a result of water shortages, nutrient deficiencies, and pests [8]. The contrast of light reflectance provides an assessment of the vegetation. Remote sensing can therefore provide a powerful tool for monitoring changes in the crop canopy over the growing season and can provide crop developmental information that is time-critical for site-specific crop management [9]. Remote sensing thus makes assessment objective faster, easier, and more reliable.

Remote sensing data has the potential and the capacity to provide spatial information at global scale of features and phenomena on earth on an almost real-time basis [4]. Use of remote sensing techniques has the potential to provide quantitative and timely information on agricultural crops over large areas, and many different methods have been developed to estimate crop yields $[10,11]$. In general, the use of remote sensing is aimed at reducing the number of samples of ground surveys, making it less expensive [12]. With the application of remote sensing in agriculture, there is potential not only in identifying crop classes but also of estimating crop yield [4].

Remote sensing applications include monitoring deforestation, wildlife inventory, crop health status assessments, and yield forecasting [12]. Researchers have used remote sensing greatly to estimate fractional intercepted photosynthetically active radiation [13] and crop parameters like leaf chlorophyll, ground cover $[12,14]$, total dry-mass accumulation [14], plant greenness [15], yield [16], nitrogen status, and many other chemical properties of vegetation [17].

Spectral measurements from crops can be used in estimating crop parameters such as leaf area index [18], plant population, and even canopy total nitrogen status during the growth cycle of the crop [19]. Vegetation indices are algorithms which simplify data from multiple reflectance bands to a single value correlating to physical vegetation parameters, such as biomass, productivity, leaf area index, or percent vegetation ground cover [14]. Single refelectance bands are combined into a vegetation index in order to minimize the effect of such factors as optical properties of the soil background, illumination, and view geometric as well as meteorological factors on the canopy radiometric properties [20].

The current conventional tobacco yield forecasts rely on seed purchase records, land area, and visual assessment of the crop. Since farmers' records may not be exhaustive, the current forecast may not be accurate. Use of yield forecasting models can be employed to avoid these problems. Some existing models relate meteorological parameters to crop yield and production, while others are purely statistical in nature [3]. Although use of models has allowed fairly good forecasting capability to be conducted, the nature and relations between yield and some parameters may not be easily determined. Statistical models, for example, are location specific, and the use of averages in developing a yield model may not reflect conditions in extreme situations. The process of collecting data can be tedious and time consuming and thus preclude large-scale investigations [21].

Remote sensing can complement or even improve the current conventional tobacco yield prediction methods used. This is because remote sensing to provides useful information on real time crop condition as well as for yield forecasting. Every substance emits, absorbs, transmits, or reflects electromagnetic radiation in a manner characteristic of the substance [17] and depending on the chemical properties of the intercepting molecule, information from analysis of the energy of parts of the light spectrum absorbed or scattered by the atomic bonds, electrons, or atoms in the intercepting molecule can be used to predict yield [22].

The current conventional tobacco yield forecasts rely on seed purchase records, land area, and visual assessment of the crop. Since farmers' records may not be exhaustive the current forecast may not be accurate [21]. Use of yield forecasting models can be employed to avoid these problems. Some existing models relate meteorological parameters to crop yield and production, while others are purely statistical in nature [3]. Although use of models has allowed fairly good forecasting capability to be conducted, the nature and relations between yield and some parameters may not be easily determined.

\section{Remote Sensing Science}

By measuring the quantity of radiation in each of the wavelengths, the plant canopy characteristics can be defined [22]. The differences in leaf colours, textures, shapes or even how the leaves are attached to plants, determine the amount of reflected, absorbed, or transmitted energy, and such relationships are used to determine spectral signatures of individual plants, which are unique to plant species [23]. Spectral signatures make it possible to use remote sensing in studying changes in specific crop conditions in the field and relate these to final yield and quality [18].

The comparison of the reflectance values at different wavelengths is used to determine plant vigour [24]. The most common index that is used for this purpose is the normalized deviation vegetative index (NDVI) [8]. Vegetation indices, as summarized by Broge and Leblanc [25], are based on the characteristic reflection of plant leaves in the visible and nearinfrared portions of light. By applying a "Vegetation Index" to the satellite imagery, concentration of green leaf vegetation can be quantified [26]. As explained by Broge and Leblanc [25], healthy vegetation has low reflection of visible light (from 0.4 to $0.7 \mu \mathrm{m}$ ), since it strongly absorbs chlorophyll for photosynthesis and, at the same time, there is high reflection 
of near-infrared light (from 0.7 to $1.1 \mu \mathrm{m}$ ). The portion of reflected near-infrared light depends on the cell structure of the leaf [27]. In fading or unhealthy leaves, photosynthesis decreases and cell structure collapses resulting in an increase of reflected visible light and a decrease of reflected nearinfrared light [25].

The normalized difference vegetation index (NDVI) has been considered to be a useful way for crop yield assessment models, using various approaches such as simple integration, to reflect vegetation greenness [29]. The index responds to changes in the amount of green biomass, chlorophyll content, and canopy water stress and, hence, is the most commonly used in assessing crop vigor, vegetation cover, and biomass production from multispectral satellite data [30]. The NDVI is calculated from the near infrared (NIR) and red (R) bands of either handheld or satellite sensors using the formular: NDVI $=($ NIR - Red $) /($ NIR + Red $)$. According to Kidwell [31] the NDVI value of each area on an image helps identify areas of varying levels of plant vigour within fields.

The validity of crop yield models with NDVI is determined by the strengths of association between the two variables included in the model [32]. It is also essential to have an understanding of the correlation existing between yield and NDVI at different phonological stages of crop for selecting appropriate date of satellite pass to include in the model [32].

Research has shown that the NDVI is directly related to the photosynthetic activity and hence energy absorption by plant canopy; typical examples include the leaf area index (LAI) and biomass chlorophyll concentration in leaves, plant productivity, and fractional vegetation cover [33]. These could also be considered when developing models for estimating seasonal biomass production for either individual species or communities. Remote sensing surveys have successfully been conducted elsewhere in forecasting yield in paddy rice [34], maize [18], and potatoes [35].

\section{Need for a Remote Sensing Based Yield Estimation Model}

Tobacco producers need to monitor crop growth and development and obtain early estimates of final yield [1]. In the current scenario, unavailability of a comprehensive method for estimating tobacco yield has often led to contradicting estimates, subjective national statistics, and general planning inefficiency by stakeholders. The current tobacco yield estimation is based on the Garvin model [21], seed tracking approach, and the statistical and crop condition assessment approaches. Such conventional methods of scouting are often labour intensive and are based on data collected from sampled area and, hence, their precision varied [21]. Variable crop conditions are only distinguishable to the very trained and experienced eye. A more objective and practical model for yield estimation could assist tobacco stakeholders with more precise data on tobacco growth characteristics, hectarage, and final yield that would be available for export [2].

Site-specific information on varieties, fertiliser management, and cultural practices may improve the accuracy of yield crop forecasting and, offers the potential to provide quantitative and timely information on agricultural crops over large areas [36]. Multispectral imaging sensors are able to view more than one particular band of energy. These bands are selected in various regions of the electromagnetic spectrum, based on the optimum range of energy being reflected by the objects observed. In-season canopy images have also been found useful in predicting yields in maize, soybean, and cotton plant canopy $[13,16,37]$.

Developing a model to forecast or estimate tobacco yield is very useful for decision making in the Zimbabwean tobacco industry [2]. A yield estimation model for tobacco could also assist stakeholders to accurately determine total energy requirements for curing [21]. For the government an accurate prediction of the crop size is a useful planning tool in view of foreign currency generated by tobacco, for determining import-export policies, government aid for farmers, and allocation of subsidies for agricultural programs [2].

By using satellite imagery instead of traditional sampling techniques, tobacco yield forecasts can be generated earlier than traditional estimates; and because they are based on images that can be constantly downloaded from the satellite, these forecasts can be updated frequently throughout the growing season, thus tracking growth response to different conditions as the season progresses [4]. The signatures from satellite imagery will then be fed into the model in order to come up with the volume estimate of the crop [16]. Remote sensing would enable observations over large areas at regular intervals, making it useful in large-scale crop modelling [22].

Use of satellite imagery would also enable the verification farmers' claims of seedbed area established, size of irrigated and dry land tobacco crop, varietal proportions in the field, and even monitor disease development adherence to legislation. Varietal distribution, nutrient, and cultural management effects can also be easily monitored and factored in the final yield forecast.

Tobacco yield estimates are essential for marketing of the crop as well as infrastructure development and policy making [2]. When estimates are overestimated, tobacco merchants supply larger volumes of money early in the season to accommodate an anticipated huge volume of leaf only for the prices to fall dramatically when the expectation is not met [2]. When crop yields are understated, merchants will typically avail less money for the leaf which will force market prices of the crop to drop in order to gain as much leaf as possible with the limited funds available. It goes without say as well that policy planning and infrastructure allocation become biased when based on tobacco estimates with a tendency to vary due to inaccuracy. Planted area estimates and field visits often present the challenge of not accurately representing the overall production picture because it is difficult to assess every farm every year due to accessibility challenges, financial constraints, and the temporal function of assessments.

There is need for a comprehensive and holistic approach to tobacco yield estimation for the nation. Remote sensing presents an interesting, cost effective, faster, comparatively cheaper, and more accurate means of determining planted area, crop vigour, and expected yield at a national level if suitably developed and applied. Satellite remote sensing 
specifically involves the use of space borne instruments to observe, analyze, and compare areas of interest for vegetative growth and development. Several platforms have become commercially available to aid the purpose of vegetative assessments. Satellite images collected over time specific crop periods can be easily accessed, compared, and used to provide key indications on crop vigour, biomass, and spatial distribution.

\section{Recommended Research}

Remote sensing application in Zimbabwe is still very limited, largely due to the perception that satellite data is expensive to obtain and complicated to process [38]. This could be as a result of research work that has focused on the high resolution spectral imagery from commercial satellites such as Quickbird which have been used extensively in more developed countries leading to wide adoption in the purposes of developing yield estimation procedures for various crops as was outlined by $\mathrm{Wu}$ et al. [35]. Indirect relationships between cereal yield and satellite derived vegetation indices have been developed and can accurately predict yields despite the economic organ not being directly assessed [39].

Satellite sensing presents the challenge of spectral confusion when imaging crops with planting dates spaced closely together or crops with near similar spectral signatures [40]. When the spectral resolution of a remote sensing instrument is comparatively low, it can be difficult to distinguish target crop species from other crops that may be in vegetative growth at the same time [41]. Spectral distinction of closely related species can be achieved by several methods such as using high spectral resolution sensors to identify specific wavelength regions that are unique to specific plant species [24]. Assuming the spectral resolution of the instrument in use is of adequate capacity such as high resolution Hyperion EO-1 platforms, discrimination can be based on the differences picked in specific wavelength regions affected by the growth and development of a species as demonstrated in the United States on trials to distinguish field peas, wheat, barley, and slashed wheat from the baseline soil reflectance [42].

Tobacco cultivation in Zimbabwe is guided by law [2] which states that tobacco can only be planted on or after the 1st of September up until the 31st of December of each growing season [19]. This narrows down the prospective window when land use change associated with tobacco area estimation can be done to practical time frames since any crop canopy reflectance's detected by satellite instruments before the 1st of September can easily be ruled out as those of flue cured tobacco. Most commercially grown crop species in Zimbabwe will not be in production by this time since they are dependent on rainfall distribution which does not normally begin until November [43]. The dominant reflection therefore detectable during September is that of the winter wheat that should be in senescence stage and ploughed lands in preparation of tobacco planting [38]. Senescencing wheat can be easily identified and separated from tobacco planted by the relatively higher reflection in the visible spectrum electromagnetic range than tobacco which would be in active growth and development. Bare soil displays a characteristic spectral signature characteristic with an increasing linear profile, making it very easy to separate the September planted tobacco crop from adjacent bare fields [38].

When the October crop is planted, its growth profile appears similar to that of September planted crops with the distinct difference of temporal spacing [38]. Therefore the two crops appear to develop parallel to each other and this again makes separation and estimation relatively easier. The position of the red edge and corresponding reflective responses in specific wavelength sections can be used accurately to distinguish crop species that occur in the same temporal time frame but of different species [38].

Unlike cereal crops, there is a direct relationship between vegetative response and crop vigour, yield and biomass unlike in wheat, maize, and sorghum where biomass becomes a function of accumulated density but does not significantly contribute to canopy reflectance [41]. It becomes plausible to argue that due to this direct relationship, yield estimation and crop vigour assessments can be more accurately assessed by remote sensing instruments than cereal crops [38] and are less subjective to bias and anomalies in data interpretation [44]. In fact, the nature of yield-canopy reflectance relationships may be reversed in crop species whose economic yield function is inversely related to biomass, one such crop being cotton [28] even though the agronomic plant parameters such as stem height, leaf number, and vegetative overall plant biomass may be positively correlated to vegetative indices [45]. Interestingly enough, spatial resolution can significantly affect the ability of a satellite sensor to identify subtle differences in crops as was demonstrated by Toulios et al. [28]. Table 1 below shows the correlation strength variations that occur due to spatial variation differences applied to a cotton field to estimate yield.

Remote sensing skills developed for Zimbabwe's flue cured tobacco estimation should seek to address the challenges of yield conflicts that may arise from tobacco with different fertilizer management regimes [2]. Small scale farmers tend to apply lower rates of fertilizer than their large scale commercial counterparts; because of this, it becomes possible to overestimate crop yields of crops that lie under communal growers.

Research work should focus on whether the model should separate low fertilizer regime crops from the standard as well as those that might be subjected to over application of fertilizer [41]. Varietal differences should also be investigated to ascertain whether the influence of varietal differences grown in the country will affect the applicability of the method in predicting feasible tobacco yields [46]. The most applicable means of utilizing remote sensing instruments for yield estimation may lie in the temporal separation ability of instruments based on different planting dates [43].

According to Garvin, [21] yield estimation is possible with plant parameters such as plant height, leaf number, and drymass, it therefore becomes feasible to use NDVI derived from tobacco fields to estimate biomass and eventually derive final yield of flue cured tobacco. Garvin also argued that varietal differences do not significantly affect the prediction potential of tobacco varieties, thus making the NDVI-yield relationship independent of varietal expression. 
TABLE 1: Correlation coefficients of spectral variables with cotton yield.

\begin{tabular}{lccc}
\hline Spectral variables & $\begin{array}{c}\text { Spectra } 2 \times 2 \mathrm{~m} \text { versus } \\
\text { Yield } 2 \times 2 \mathrm{~m}\end{array}$ & $\begin{array}{c}\text { Spectra } 10 \times 10 \mathrm{~m} \text { versus } \\
\text { Yield } 10 \times 10 \mathrm{~m}\end{array}$ & $\begin{array}{c}\text { Spectra } 20 \times 20 \mathrm{~m} \text { versus } \\
\text { Yield } 20 \times 20 \mathrm{~m}\end{array}$ \\
\hline 12/07_NDVI & 0.54 & 0.71 & 0.68 \\
12/07_SAVI & 0.54 & 0.71 & 0.68 \\
12/07_IR & 0.44 & 0.68 & 0.69 \\
12/07_RED & 0.15 & 0.57 & 0.67 \\
12/07_Green & 0.24 & 0.61 & 0.68 \\
12/07_NDVI & 0.55 & 0.72 & 0.7 \\
12/07_SAVI & 0.55 & 0.72 & 0.7 \\
12/07_IR & 0.46 & 0.68 & 0.69 \\
12/07_RED & 0.16 & 0.59 & 0.67 \\
12/07_Green & 0.27 & 0.63 & 0.68 \\
12/07_NDVI & 0.24 & 0.61 & 0.68 \\
12/07_SAVI & 0.24 & 0.61 & 0.68 \\
12/07_IR & 0.21 & 0.6 & 0.69 \\
12/07_RED & 0.24 & 0.62 & 0.69 \\
12/07_Green & 0.27 & 0.63 & 0.69 \\
\hline
\end{tabular}

Source: Toulios et al. [28].

There are several vegetative indices that were developed for purposes of monitoring and quantifying crop growth and development. Among these are the NDVI [14], EVI, and SAVI [47], and correlation between these and the biophysical parameters of tobacco crop must be studied. The tobacco cropping season spans from September to April [19]. The planting periods for these are continuous from September to December [2]. Research should focus on identifying a suitable index that can separate the crops in the different planting regimes and then estimate yield separately. For each planting regime, there is also need for establishing the temporal window for collecting remote sensing data in order to achieve the best prediction ability [47].

The tobacco sector in Zimbabwe is divided into smallholder and commercial sector, with the former comprising $80 \%$ of total tobacco produced in the country [2]. The challenge of the different land sizes in the two sectors still has to be overcome by identifying suitable satellite platform, with sufficient spectral resolution to separate the tobacco crop from the adjacent competing crops and noncrop vegetative surfaces.

The identified suitable index should be strongly correlated with tobacco in season dry mass and yield for it to be suitable for use in crop yield forecasting [47]. However, another approach could be that of using the vegetative indices to establish tobacco cropped area [43] and then apply the long-term area yield relationship from government and nongovernmental statistical departments and develop models that can be used to estimate yield from remote sensing derived cropped area. For the experimentation purposes, use of hand held remote sensor like the multispectral radiometer can be useful in characterising the spectral response properties of the different phenological stage of tobacco, for the varieties and for different fertiliser levels. The information can then be applied in operational yield forecasting of tobacco. It is recommended that further research be done to establish spectral ratios for different satellite platforms that can be utilised for the different land size situations where differently spectral resolutions could be required.

\section{Acknowledgment}

The authors are grateful to the Tobacco Research Board/Kutsaga Research Station for funding this series of experiments on "Developing flue cured tobacco crop area and yield forecasting models using remote sensing and agronomic techniques." The authors declare that there is no conflict of interests. The Tobacco Research Board is a research institution and the first author of the paper is a registered DPhil student with the University of Zimbabwe, with the other three as supervisors. This paper is the third of the five papers developed from the five objectives of the DPhilAg studies. The TRB strives to publish all the research work that is carried out and not for financial gain.

\section{References}

[1] Tobacco Facts, "Zimbabwe Tobacco industry," 2009, http:// www.tobacco-facts.net/tobacco-industry/zimbabwe-tobaccoindustry.

[2] Tobacco Industries Marketing Board (T.I.M.B), "Annual report and Accounts for the Year Ended 30 June, 2004," T.I.M.B, Harare, Zimbabwe, 2005.

[3] FAO, Agrometeorological Crop Forecasting, Food and Agriculture Organization (FAO) of the United Nations, Rome, italy, 2008.

[4] C. A. Reynolds, M. Yitayew, D. C. Slack, C. F. Hutchinson, A. Huetes, and M. S. Petersen, "Estimating crop yields and production by integrating the FAO Crop Specific Water Balance model with real-time satellite data and ground-based ancillary data," 
International Journal of Remote Sensing, vol. 21, no. 18, pp. 34873508, 2000.

[5] T. R. Wheeler, P. Q. Craufurd, R. H. Ellis, J. R. Porter, and P. V. Vara Prasad, "Temperature variability and the yield of annual crops," Agriculture, Ecosystems and Environment, vol. 82, no. 13, pp. 159-167, 2000.

[6] J. Wu, D. Wang, and M. E. Bauer, "Assessing broadband vegetation indices and QuickBird data in estimating leaf area index of corn and potato canopies," Field Crops Research, vol. 102, no. 1, pp. 33-42, 2007.

[7] R. G. Keller, V. Harder, and J. Seeley, "Introduction to Basic Principles of Remote Sensing," Department of Geological Sciences. UTEP, 2008, http://www.geo.utep.edu/.

[8] R. D. Jackson, P. N. Slater, and P. J. Pinter Jr., "Discrimination of growth and water stress in wheat by various vegetation indices through clear and turbid atmospheres," Remote Sensing of Environment, vol. 13, no. 3, pp. 187-208, 1983.

[9] S. Landau, R. A. C. Mitchell, V. Barnett, J. J. Colls, J. Craigon, and R. W. Payne, "A parsimonious, multiple-regression model of wheat yield response to environment," Agricultural and Forest Meteorology, vol. 101, no. 2-3, pp. 151-166, 2000.

[10] J. A. Moran, A. K. Mitchell, G. Goodmanson, and K. A. Stockburger, "Differentiation among effects of nitrogen fertilization treatments on conifer seedlings by foliar reflectance: a comparison of methods," Tree Physiology, vol. 20, no. 16, pp. 1113-1120, 2000.

[11] M. E. Bausch, "The role of remote sensing in determining the distribution and yield of crop," Advances in Agronomy, vol. 27, pp. 271-304, 2000.

[12] P. C. Doraiswamy, T. R. Sinclair, S. Hollinger, B. Akhmedov, A. Stern, and J. Prueger, "Application of MODIS derived parameters for regional crop yield assessment," Remote Sensing of Environment, vol. 97, no. 2, pp. 192-202, 2005.

[13] L. Serrano, Recent Advances in Quantitative Remote Sensing: Papers from the Second International Symposium, Taylor \& Francis, Bristol, Pa, USA, 2006.

[14] C. J. Tucker, "Red and photographic infrared linear combinations for monitoring vegetation," Remote Sensing of Environment, vol. 8, no. 2, pp. 127-150, 1979.

[15] G. Asrar, M. Fuchs, E. T. Kanemasu, and J. L. Hatfield, "Estimating absorbed photosynthetic radiation and leaf area index from spectral reflectance in wheat," Agronomy Journal, vol. 76, pp. 300-306, 1984.

[16] B. L. Ma, L. M. Dwyer, C. Costa, E. R. Cober, and M. J. Morrison, "Early prediction of soybean yield from canopy reflectance measurements," Agronomy Journal, vol. 93, no. 6, pp. 1227-1234, 2001.

[17] V. I. Adamchuk, R. L. Perk, and J. S. Schepers, "Applications of Remote Sensing in Site-Specific Management," Tech. Rep. EC 03-702, University of Nebraska Cooperative Extension Publication, 2003.

[18] A. D. Baez-Gonzalez, J. R. Kiniry, S. J. Maas et al., "Large-area maize yield forecasting using leaf area index based yield model," Agronomy Journal, vol. 97, no. 2, pp. 418-425, 2005.

[19] D. Haboudane, N. Tremblay, J. R. Miller, and P. Vigneault, "Remote estimation of crop chlorophyll content using spectral indices derived from hyperspectral data," IEEE Transactions on Geoscience and Remote Sensing, vol. 46, no. 2, pp. 423-437, 2008.

[20] M. Monteith, Principles of Environmental Physics, Edward Arnold, London, UK, 1990.
[21] R. T. Garvin, "Flue cured tobacco yield estimation in crop research," Zimbabwe Science News, vol. 19, no. 5-6, pp. 65-67, 1985.

[22] O. Mutanga, Hyperspectral Remote Sensing of Tropical Grass Quality and Quantity [Ph.D. thesis], Wageningen University, ITC Dissertation Number 111, The Netherlands, 2004.

[23] J. Nowatzki, R. Andres, and K. Kyllo, "Agricultural Remote Sensing Basics," 2004, North Dakota State University Agriculture and University Extension, 2004, http://www.ag.ndsu.edu/.

[24] H. W. Gausman and D. E. Escobar, "Discrimination among plant nutrient deficiencies with reflectance measurements," Annual Review of Crop Physiology, vol. 244, 1973.

[25] N. H. Broge and E. Leblanc, "Comparing prediction power and stability of broadband and hyperspectral vegetation indices for estimation of green leaf area index and canopy chlorophyll density," Remote Sensing of Environment, vol. 76, no. 2, pp. 156172, 2001.

[26] A. Viña, A. A. Gitelson, D. C. Rundquist, G. Keydan, B. Leavitt, and J. Schepers, "Monitoring maize (Zea mays L.) phenology with remote sensing," Agronomy Journal, vol. 96, no. 4, pp. 11391147, 2004.

[27] S. Moulin, A. Bondeau, and R. Delécolle, "Combining agricultural crop models and satellite observations: from field to regional scales," International Journal of Remote Sensing, vol. 19, no. 6, pp. 1021-1036, 1998.

[28] L. Toulios, D. Pateras, G. Zerva, T. A. Gemtos, and T. H. Markinos, "Combining satellite images and cotton yield maps to evaluate field variability inprecision farming," in Proceedings of the World Cotton Research Conference, F. M. Gillham, Ed., pp. 534-539, Athens, Greece, 1998.

[29] A. K. Prasad, L. Chai, R. P. Singh, and M. Kafatos, "Crop yield estimation model for Iowa using remote sensing and surface parameters," International Journal of Applied Earth Observation and Geoinformation, vol. 8, no. 1, pp. 26-33, 2006.

[30] S. Balaselvakumar and S. Saravanan, "Remote sensing techniques for agriculture survey," 2006, http://www.gisdevelopment.net/application/agriculture/overview/agrio014.htm.

[31] K. B. Kidwell, Global Vegetation Index User's Guide, U.S. Department of Commerce/National Oceanic and Atmospheric Administration/National Environmental Satellite Data and Information Service/National Climatic Data Center/Satellite Data Services Division, 1990.

[32] C. W. Jayroe, W. H. Baker, and A. B. Greenwalt, "Using multispectral aerial imagery to evaluate crop productivity," Crop Management, 2005.

[33] R. B. Myneni, F. G. Hall, P. J. Sellers, and A. L. Marshak, "Interpretation of spectral vegetation indexes," IEEE Transactions on Geoscience and Remote Sensing, vol. 33, no. 2, pp. 481-486, 1995.

[34] http://www.geospatialworld.net/paper/application/ArticleView.aspx?aid=255.

[35] J. Wu, D. Wang, and M. E. Bauer, "Assessing broadband vegetation indices and QuickBird data in estimating leaf area index of corn and potato canopies," Field Crops Research, vol. 102, no. 1, pp. 33-42, 2007.

[36] J. G. P. W. Clevers, "Application of a weighted infrared-red vegetation index for estimating leaf Area Index by Correcting for Soil Moisture," Remote Sensing of Environment, vol. 29, no. 1, pp. 25-37, 1989.

[37] V. Thomas, P. Treitz, J. H. Mccaughey, T. Noland, and L. Rich, "Canopy chlorophyll concentration estimation using hyperspectral and lidar data for a boreal mixedwood forest in 
Northern Ontario, Canada," International Journal of Remote Sensing, vol. 29, no. 4, pp. 1029-1052, 2008.

[38] Tobacco Research Board (T.R.B), "Annual report and Accounts for the Year Ended 30 June, 2011,” TRB, Harare, Zimbabwe, 2012.

[39] K. P. Gallo and T. K. Flesch, "Large-area crop monitoring with the NOAA AVHRR: estimating the silking stage of corn development," Remote Sensing of Environment, vol. 27, no. 1, pp. 73-80, 1989.

[40] E. B. Knipling, "Physical and physiological basis for the reflectance of visible and near-infrared radiation from vegetation," Remote Sensing of Environment, vol. 1, no. 3, pp. 155-159, 1970.

[41] C. P. Ferri, A. R. Formaggio, and M. A. Schiavinato, "Narrow band spectral indexes for chlorophyll determination in soybean canopies [Glycine max (L.) Merril]," Brazilian Journal of Plant Physiology, vol. 16, no. 3, pp. 131-136, 2004.

[42] J. L. Hatfield, A. A. Gitelson, J. S. Schepers, and C. L. Walthall, "Application of spectral remote sensing for agronomic decisions," Agronomy Journal, vol. 100, no. 3, supplement, pp. S117S131, 2008.

[43] D. Manatsa, I. W. Nyakudya, G. Mukwada, and H. Matsikwa, "Maize yield forecasting for Zimbabwe farming sectors using satellite rainfall estimates," Natural Hazards, vol. 59, no. 1, pp. 447-463, 2011.

[44] C. Yang, J. H. Everitt, and J. M. Bradford, "Using high resolution QuickBird satellite imagery for cotton yield estimation," in Proceedings of the ASAE Annual International Meeting, Paper number 041119, pp. 893-904, August 2004.

[45] T. N. Carlson and D. A. Ripley, "On the relation between NDVI, fractional vegetation cover, and leaf area index," Remote Sensing of Environment, vol. 62, no. 3, pp. 241-252, 1997.

[46] F. M. Marumbwa, A. Murwira, E. K. Madamombe, S. Kusangaya, and F. Tererai, "Remotely sensing of irrigation water use in Mazowe Catchment, Zimbabwe," Zimbabwe National Water Authority (ZINWA), Department of Geography \& Environmental Science, University of Zimbabwe, 2006.

[47] Z. Jiang, A. R. Huete, K. Didan, and T. Miura, "Development of a two-band enhanced vegetation index without a blue band," Remote Sensing of Environment, vol. 112, pp. 3833-3845, 2008. 


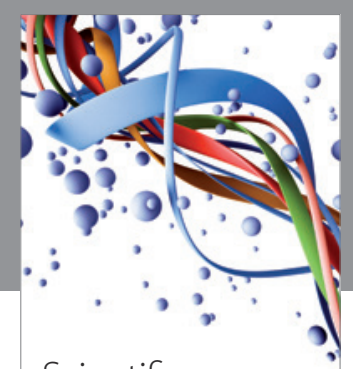

Scientifica
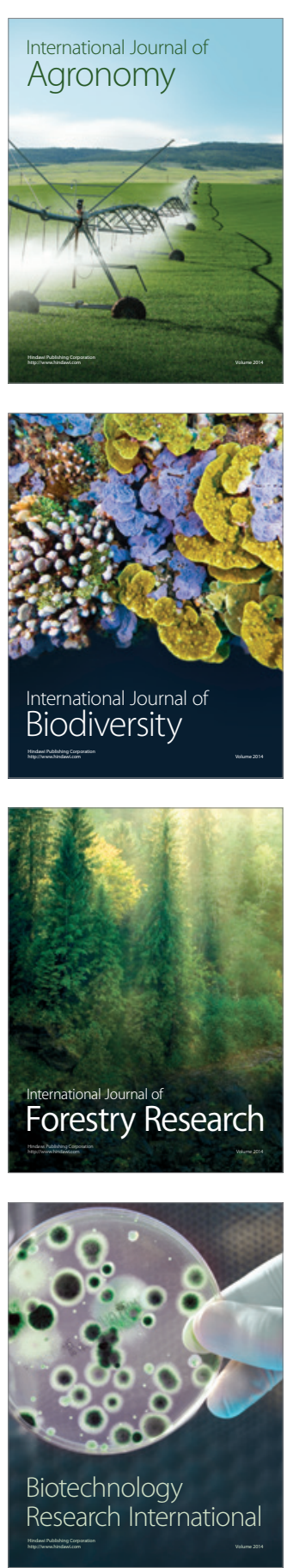
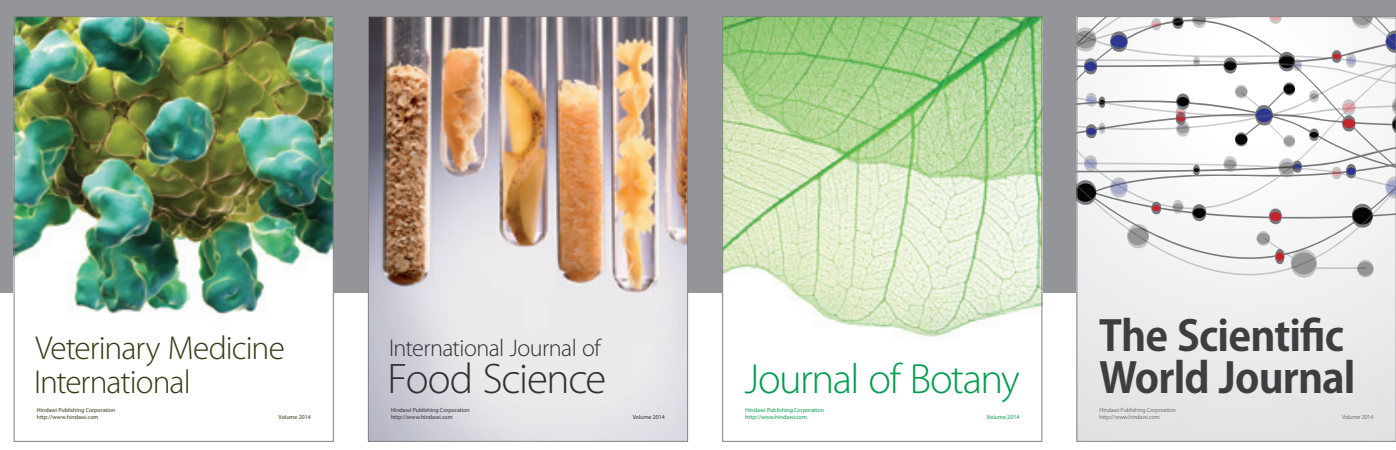

The Scientific World Journal
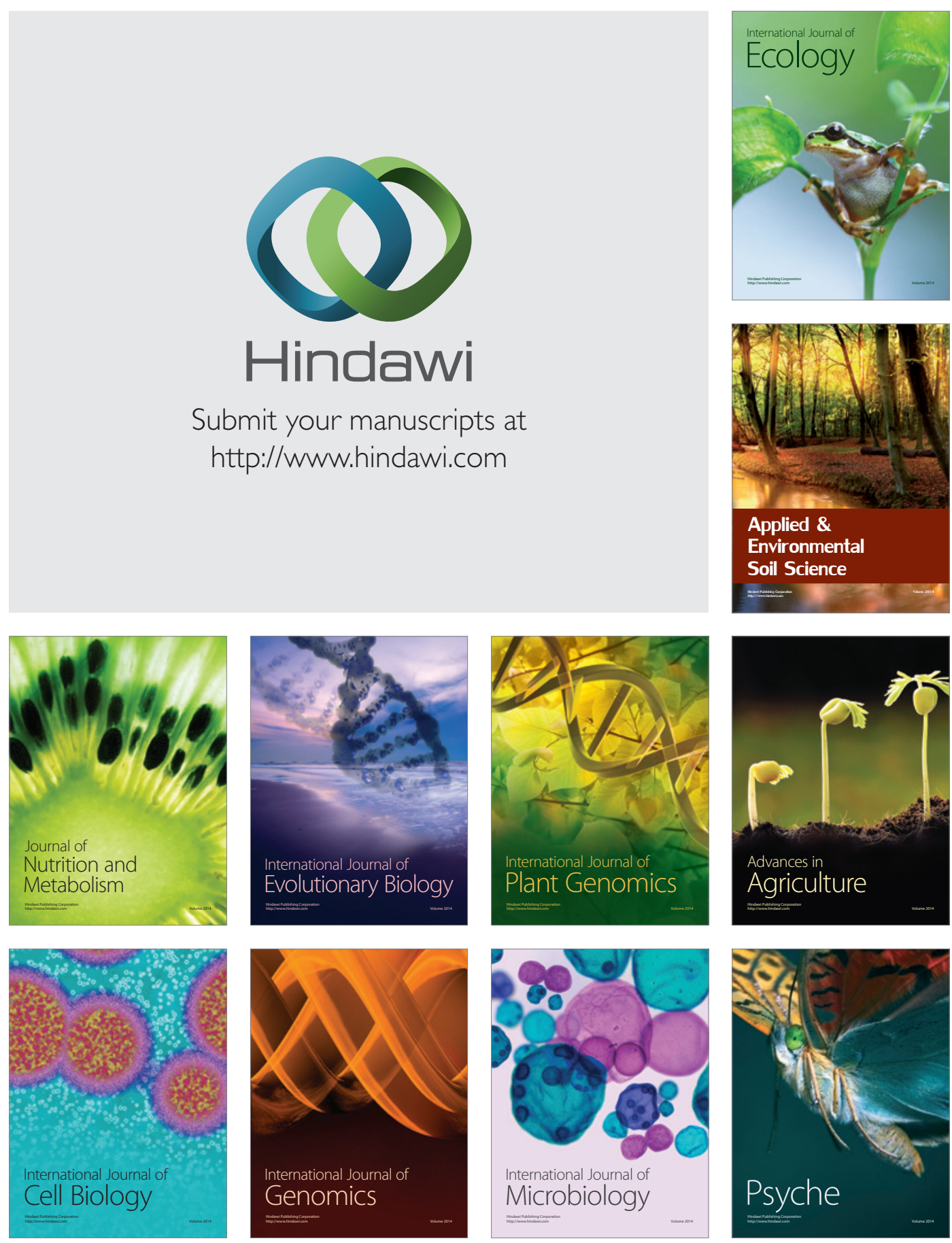